\title{
Article \\ The Study of POSS/Polyurethane as a Consolidant for Fragile Cultural Objects
}

\author{
Xing Zhao ${ }^{1}$, Lang Guo ${ }^{2}$, Liqin Wang ${ }^{1,2, *}$, Ziming Wang ${ }^{1}$, Meiman Peng ${ }^{2}$, Liping Zheng ${ }^{3}$ and Qing Niu ${ }^{4}$ \\ 1 Key Laboratory of Cultural Heritage Research and Conservation, Northwest University, \\ Ministry of Education, Xi'an 710127, China; zhaoxing@nwu.edu.cn (X.Z.); \\ wangziming@stumail.nwu.edu.cn (Z.W.) \\ 2 School of Cultural Heritage, Northwest University, Xi'an 710127, China; guolang5617@163.com (L.G.); \\ wbpengmm@stumail.nwu.edu.cn (M.P.) \\ 3 School of History and Society, Chongqing Normal University, Chongqing 401331, China; \\ zhengliping@stumail.nwu.edu.cn \\ 4 Xi'an Cultural Heritage Promotion Centre, Xi'an 710001, China; katherine_niu@163.com \\ * Correspondence: wangliqin@nwu.edu.cn
}

check for updates

Citation: Zhao, X.; Guo, L.; Wang, L.; Wang, Z.; Peng, M.; Zheng, L.; Niu, Q. The Study of POSS/Polyurethane as a Consolidant for Fragile Cultural Objects. Coatings 2022, 12, 153. https://doi.org/10.3390/ coatings12020153

Academic Editor: Maurizio Licchelli

Received: 31 December 2021

Accepted: 25 January 2022

Published: 27 January 2022

Publisher's Note: MDPI stays neutral with regard to jurisdictional claims in published maps and institutional affiliations.

Copyright: (C) 2022 by the authors. Licensee MDPI, Basel, Switzerland. This article is an open access article distributed under the terms and conditions of the Creative Commons Attribution (CC BY) license (https:// creativecommons.org/licenses/by/ $4.0 /)$.

\begin{abstract}
Moisture-curable polyurethane (MCPU) is a specifically designed material for the consolidation of fragile cultural objects in high-humidity environments. In order to solve the problem of its susceptibility to yellowing due to heat ageing, polyhedral oligomeric silsesquioxane (POSS) was added to the MCPU to prepare POSS/MCPU. The appearance, stability and mechanical properties of the POSS/MCPU films were characterized using a UV-Vis spectrophotometer, a gloss meter, a colorimeter, a thermal analyzer and a universal material testing machine. The results showed that the films are colorless and transparent and have a light transmission of over $80 \%$. The addition of POSS has almost no effect on the chromaticity of the MCPU, while the thermal stability of the POSS/MCPU is improved compared to the pristine MCPU. The modified film is 2.50 times more resistant to yellowing by heat. The addition of POSS also simultaneously enhances the strength and toughness of the film. Using POSS/MCPU to reinforce the fragile object, the material was found to be significantly effective, indicating it has the potential to be used during the extraction of fragile cultural objects from archaeological sites.
\end{abstract}

Keywords: conservation materials; moisture-curable polyurethane; POSS; consolidant

\section{Introduction}

Cultural objects are physical carriers of human civilization and are a key to revealing the lost history of mankind. After thousands of years of burial, cultural objects, especially organic ones, often become fragile and are subject to destruction. The organic objects found in archaeological sites are often too fragile to be extracted. It is therefore essential to take appropriate measures to increase the strength of these objects.

Consolidation with chemical materials is an effective means of enhancing the strength of fragile objects. Acrylates [1-4], polyethylene and its derivatives [5], epoxy resins [6,7] and silicones [8-10] are commonly used as consolidants for cultural objects at normal atmospheric humidity. The environments at archaeological sites such as tombs and caves are often very humid, however, with relative humidity sometimes reaching over $90 \%$. In such environments, acrylates, polyethylene and their derivatives blanch severely or even fail to cure [11]. Epoxy resin has a high mechanical strength and is generally used for stone relics rather than fragile organic cultural objects. Silicone has poor adhesive properties and does not provide sufficient bonding for fragile organic objects. Menthol [12,13], cyclododecane and veratraldehyde [14-16] perform excellently when used for the extraction of fragile organic objects, but their use as temporary reinforcement materials generally requires 
secondary treatment, which can be damaging to fragile objects. In summary, there are few materials suitable for use in high-humidity environments.

A novel moisture-curable polyurethane has been developed specifically to address the challenges of extracting fragile organic cultural objects in high-humidity environments [17]. The material can be cured at $30-100 \%$ relative humidity to form a colorless, transparent film with a flat surface and excellent mechanical properties. It is effective for the reinforcement of fragile organic objects but is susceptible to yellowing under UV light and heat conditions. In a previous study, we enhanced the yellowing resistance of the films under UV ageing by introducing hindered amine light stabilizers [18]. However, the issues of thermal stability and yellowing susceptibility to thermal ageing have not yet been addressed.

Inorganic-organic hybrids have a high thermal and oxidative stability due to the synergy between the inorganic and organic components. Polyhedral oligomeric silsesquioxane (POSS), a class of inorganic-organic nanohybrid materials with a backbone composed partly of $\mathrm{Si}-\mathrm{O}-\mathrm{Si}$, can be dispersed into other materials at the molecular or nano level, which can effectively improve the stability of these materials [19-24]. Lewicki et al. [25] carried out thermogravimetric analysis (TGA) and thermal volatilization analysis (TVA) on the thermal degradation properties of POSS/PU hybrid elastomers. They found that the modified PU was more thermally stable and had significantly lower volatile degradation products, with a $30{ }^{\circ} \mathrm{C}$ increase in degradation onset temperature. Pielichowski et al. [21] incorporated POSS into PU. They found that the modified polymers had the highest thermal stability when the POSS content was between 4 and $6 \mathrm{wt}$.\%. Lu et al. [26] used octaphenyl POSS and vinyl POSS as modifiers for polyurethane elastomers (PUE). The best mechanical properties of POSS/PUE were obtained when POSS was added at 3\%. Their group also found that when the octaphenyl POSS content was $5 \mathrm{wt} \%$, a large number of agglomerates appeared with high-speed shear dispersion and few agglomerates appeared when using ultrasonic dispersion, indicating that the latter was more effective in dispersing the POSS [27].

The above studies demonstrated the potential of POSS to improve the thermal stability of PU, but further exploration is still required for moisture-curable polyurethane, which is the focus of this study. The impact of POSS on heritage is also an element of interest. Therefore, this study proposes to use epoxy POSS (POSS) to modify MCPU. The effect of its application to delicate samples is also investigated.

\section{Materials and Methods}

\subsection{Materials}

The materials used for this research were as follows: Isophorone diisocyanate (IPDI, 99\%, Aladdin Bio-Chem Technology Co., Ltd., Shanghai, China); polyethylene glycol 600 (PEG600, Aladdin Bio-Chem Technology Co., Ltd., Shanghai, China); dibutyltin dilaurate (DBTDL, 95\%, Aladdin Bio-Chem Technology Co., Ltd., Shanghai, China); ethyl acetate (AR, Kolon Industries, Inc., Chengdu, China); and epoxy POSS (POSS, shown as Figure 1, kindly supplied by Xiaoyan Ma, Northwestern Polytechnical University, Xi'an, China).
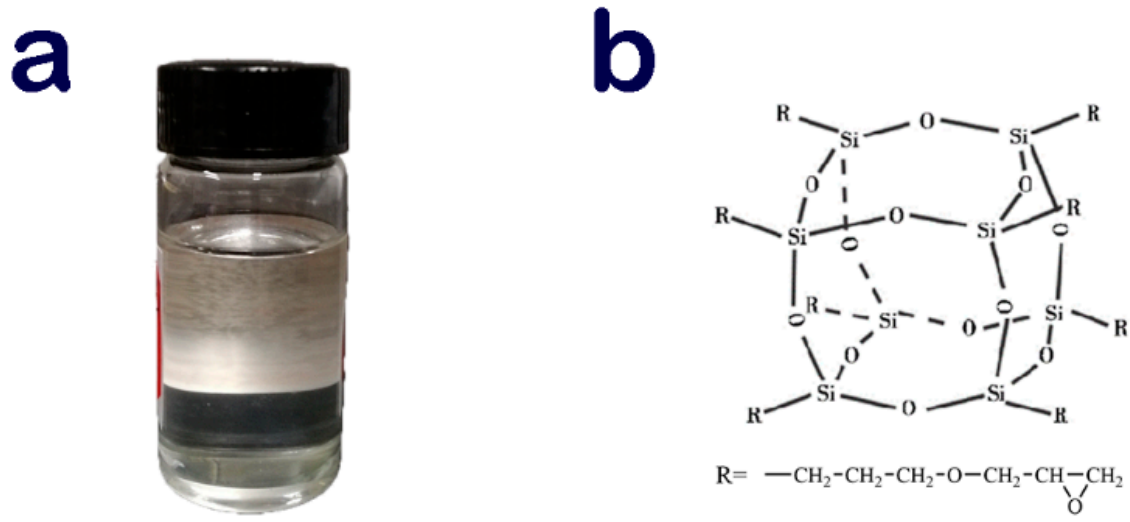

Figure 1. Photograph (a) and chemical structure (b) of POSS. 


\subsection{Preparation of $M C P U$ and $P O S S / M C P U$}

Synthesize MCPU with a 3:1:0.01 M ratio of IPDI/PEG600/DBTDL. Preheat PEG600 and DBTDL at $40^{\circ} \mathrm{C}$ for $0.5 \mathrm{~h}$ in a three-necked flask equipped with a mechanical stirrer, a condenser tube and a temperature sensor. Then, add IPDI. Continue to react at $60^{\circ} \mathrm{C}$ for $3 \mathrm{~h}$ until a white, thick production of MCPU develops. [17] Then, dissolve the prepolymer in ethyl acetate to get a $20 \mathrm{wt} . \%$ MCPU solution.

Add $8 \mathrm{wt} . \%$ POSS to the MCPU prepolymer solution and ultrasonically disperse it for $1 \mathrm{~h}$ at $70{ }^{\circ} \mathrm{C}$ using a KQ2200DB ultrasonic shaker (Kunshan Ultrasonic Instruments Co., Ltd., Kunshan, China) to prepare the POSS/MCPU.

\subsection{Preparation and Ageing of MCPU and POSS/MCPU Films}

Drop $3 \mathrm{~mL}$ of a $10 \mathrm{wt} . \%$ MCPU solution of ethyl acetate onto a slide. Let it stand in an environment with a relative humidity of $100 \%$ to obtain an MCPU film. Prepare the POSS/MCPU film by using the same method.

Place MCPU and POSS/MCPU films in a DHG-9015A oven (Yiheng Instruments Co., Ltd., Shanghai, China) for thermal ageing with the temperature set at $120^{\circ} \mathrm{C}$.

\subsection{Light Transmission Test}

The transmittance of the films was measured using an Hitaichi U2001 UV-Visible spectrophotometer (Hitachi, Ltd., Tokyo, Japan) in the wavelength range of 190 to $1100 \mathrm{~nm}$.

\subsection{Chromaticity Test}

Characterization of the appearance of the sample was conducted using a VS 450 colorimeter (X-rite, Inc., Grand Rapids, MI, USA). The CIE L*a*b* color system was adopted, where $\mathrm{L}^{*}$ indicates luminosity; $\mathrm{a}^{*}$ from positive to negative indicates colors from red to green; and $b^{*}$ from positive to negative indicates colors from yellow to blue. The color difference $\Delta \mathrm{E}$ was calculated by using the following formula.

$$
\Delta \mathrm{E}=\sqrt{\left(\Delta \mathrm{L}^{*}\right)^{2}+\left(\Delta \mathrm{a}^{*}\right)^{2}+\left(\Delta \mathrm{b}^{*}\right)^{2}}
$$

$\Delta \mathrm{L}^{*}, \Delta \mathrm{a}^{*}$ and $\Delta \mathrm{b}^{*}$ are the changes of $\mathrm{L}^{*}, \mathrm{a}^{*}$ and $\mathrm{b}^{*}$, respectively. Each sample was measured three times and averaged.

\subsection{Molecular Weight Determination}

The molecular weights of the material were measured using a 1260 high-performance liquid chromatograph (Agilent Technologies, Inc., Santa Clara, CA, USA). Two chromatographic columns, PL 1110-6100 $(7.5 \mathrm{~mm} \times 300 \mathrm{~mm}, 10 \mu \mathrm{m})$ and PL 1110-6540 $(7.5 \mathrm{~mm} \times 300 \mathrm{~mm}, 5 \mu \mathrm{m})$, were connected in series, and the following parameters were set: column temperature: $35^{\circ} \mathrm{C}$; flow rate: $1 \mathrm{~mL} \cdot \mathrm{min}^{-1}$; injection volume: $50 \mu \mathrm{L}$; and solvent: DMF. A differential refractive index detector was used for detection.

\subsection{Thermogravimetric Analysis}

The thermal properties of the films were tested using a TGA/DSC $3+$ simultaneous thermal analyzer (Mettler Toledo, Zurich, Switzerland) with a heating rate of $15^{\circ} \mathrm{C} \cdot \mathrm{min}^{-1}$, a temperature range of 50 to $1000{ }^{\circ} \mathrm{C}$ and a nitrogen atmosphere with a flow rate of $50 \mathrm{~mL} \cdot \mathrm{min}^{-1}$.

\subsection{Mechanical Property Tests}

The tensile strength of the film was measured using a QT-1176 testing machine (Gaotai Testing Instruments Co., Ltd., Dongguan, China) with a sample size of $45 \mathrm{~mm} \times 25 \mathrm{~mm}$ and a standard distance of $20 \mathrm{~mm}$, at a constant speed of $10 \mathrm{~mm} \cdot \mathrm{min}^{-1}$. 


\subsection{Scanning Electron Microscope Analysis}

The microstructures of films were observed by a Quanta 450 FEG thermal field emission ESEM (FEI Technologies, Inc., Hillsboro, OR, USA) after brittle failure of sampled liquid nitrogen. The voltage was $20 \mathrm{kV}$ and the magnification was 2500 times. The imaging mode was high vacuum secondary electron imaging.

\subsection{Simulation Experiments}

Spray an appropriate amount of distilled water onto the surface of the aged silk samples to simulate the condition of silk artefacts excavated in humid environments. After the sample has dried, draw up an amount of $8 \mathrm{wt} . \%$ POSS/MCPU ethyl acetate solution to treat the aged silk samples. Leave them to stand in a plexiglass box. The plexiglass box should hold a sufficient amount of water at the bottom and the sample should be placed on the upper layer. The relative humidity inside the box should be $90 \%$ or more.

\section{Results}

\subsection{Film Performance Results}

As shown in Figure 2, the light transmission of MCPU and POSS/MCPU films were both greater than $80 \%$ in the spectral range of 400 to $800 \mathrm{~nm}$, which is consistent with our previously published data [17]. In addition, there was little difference in the $\mathrm{L}^{*}, \mathrm{a}^{*}$ and $\mathrm{b}^{*}$ values of the films. The color-difference value $\Delta \mathrm{E}$ between the two films was 0.72 , which is unrecognizable to the naked eye. The modification has little or no effect on the color of the film.

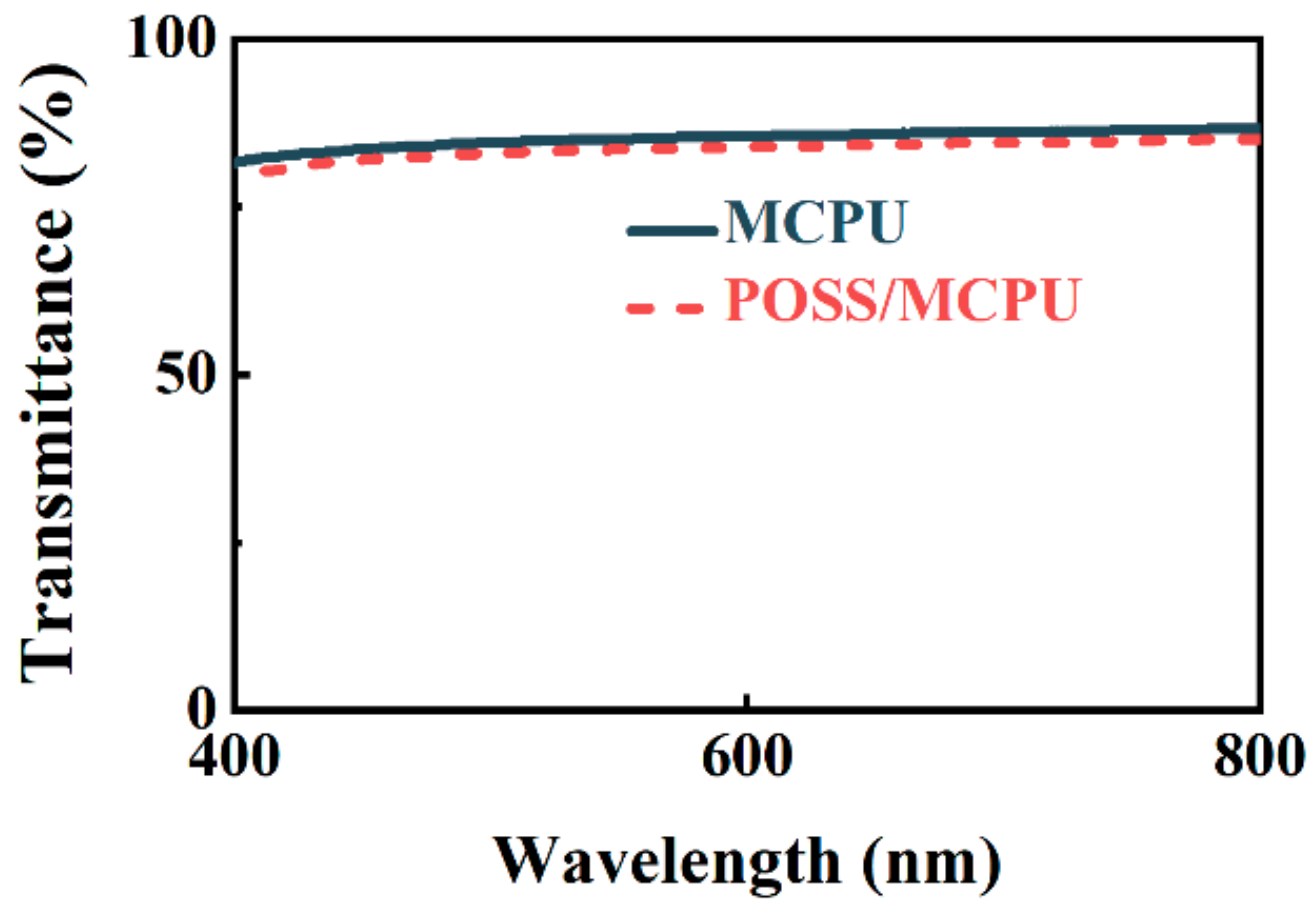

Figure 2. Light transmission of MCPU and POSS/MCPU.

Figure 3 shows the TG-DTG curves for the MCPU and POSS/MCPU at a temperaturerise rate of $15^{\circ} \mathrm{C} \cdot \mathrm{min}^{-1}$. Both MCPU and POSS/MCPU have two decomposition stages. After the addition of POSS, the initial and terminal decomposition temperatures of the films were increased from 316 to $319^{\circ} \mathrm{C}$ and from 402 to $418^{\circ} \mathrm{C}$, respectively. This indicates an increase in the thermal stability of the film. It is worth noting that the maximum rate temperatures of the POSS/MCPU are slightly shifted toward lower temperatures, which contradicts previous research [21]. Despite this, the decomposition rate of POSS/MCPU remained smaller than that of the pristine MCPU until $394{ }^{\circ} \mathrm{C}$, when the decomposition 
rate of POSS/MCPU exceeded that of the pristine MCPU. This suggests that the addition of POSS somewhat inhibits decomposition at low temperatures and raises the decomposition temperature of the polymer. This may be related to the fact that POSS contains $\mathrm{Si}-\mathrm{O}$, $\mathrm{Si}-\mathrm{C}$ bonds and $\mathrm{Si}-\mathrm{O}-\mathrm{Si}$ networks, which have larger bond energies and are less prone to breakage. The side chain groups of POSS may also reduce the molecular mobility of the PU polymer [21,28], as well as reducing the rate of release of volatiles [21], both of which contribute to a lower rate of thermal decomposition of the polymer.
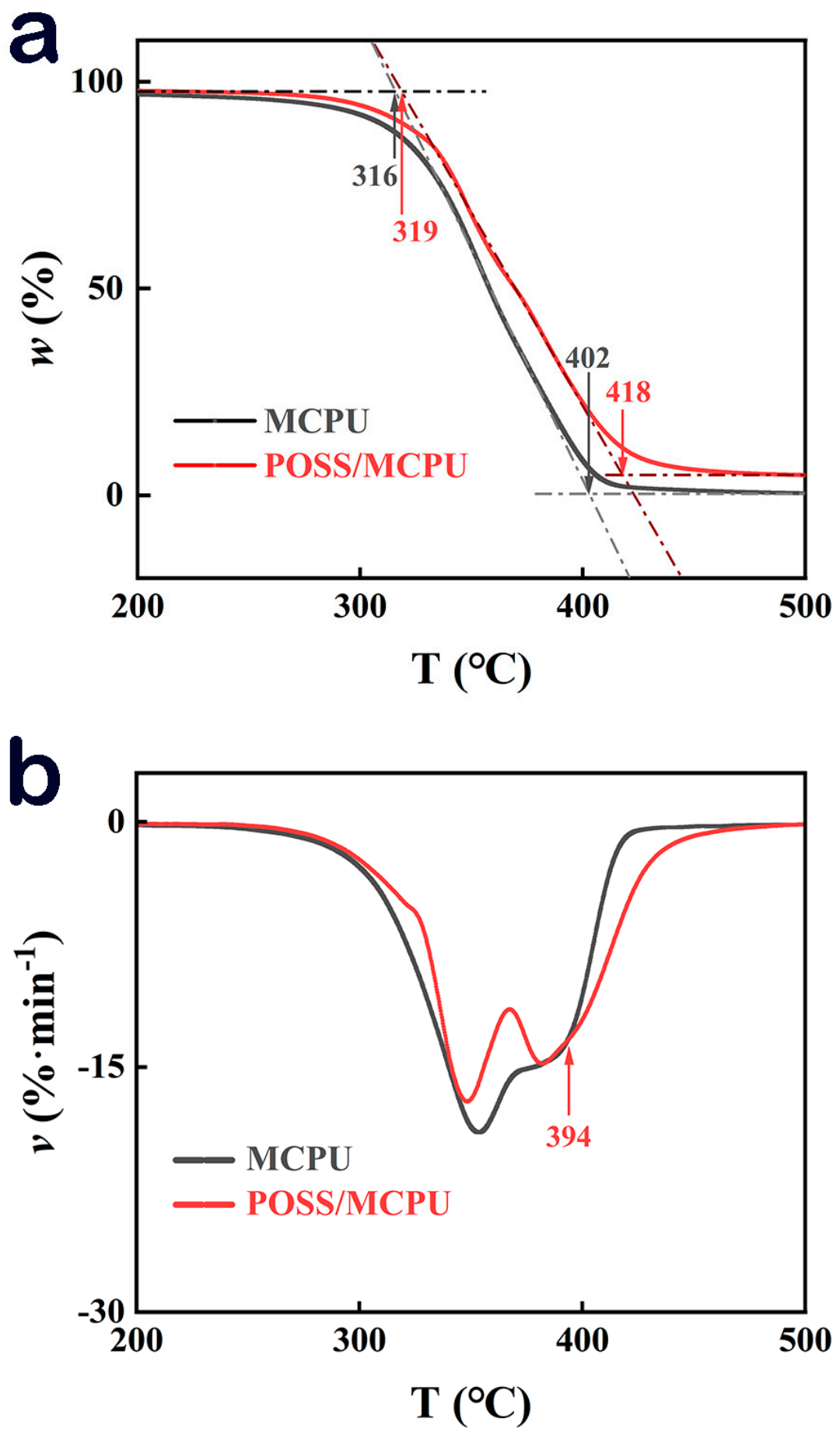

Figure 3. TG (a) and DTG (b) curves of MCPU and POSS/MCPU.

Based on the kinetics calculations of thermal decomposition [18], the decomposition activation energy was increased from 125.25 to $165.71 \mathrm{~kJ} \cdot \mathrm{mol}^{-1}$ with the addition of POSS. 
The energy barriers that need to be crossed for thermal decomposition are higher. As a result, thermal decomposition becomes more difficult and the thermal stability of the material increases. Similarly, Vyazovkin used clay to modify polystyrene polymer; the composite materials obtained had an increased resistance to thermo-oxidative degradation and greater activation energy [28].

The most obvious change in the MCPU during thermal ageing is yellowing, so the $\Delta \mathrm{b}^{*}$ value representing the change in yellow color in the CIE $\mathrm{L}^{*} \mathrm{a}^{*} \mathrm{~b}^{*}$ system was used as an indicator to represent the degree of ageing of the samples. Figure 4 shows the variation of $\triangle \mathrm{b}^{*}$ values for MCPU and POSS/MCPU with ageing time under $120^{\circ} \mathrm{C}$ ageing conditions. The degree of yellowing is positively correlated with the ageing time in both cases (the fitted equations have been included in the figures). The two critical values for the colordifference values are generally considered to be 3 and 6 , representing recognizable color change and significant color differences, respectively. According to the Lambert-Beer law, the color difference is proportional to the thickness. Since the thickness of the experimental sample is much greater than the thickness in actual use, $\Delta b^{*}=6$ was chosen as the ageing endpoint in this experiment. The MCPU and POSS/MCPU reached their ageing endpoints at approximately 8.32 and $20.78 \mathrm{~h}$ respectively, with the latter being 2.50 times more resistant to yellowing than the former. POSS significantly improved the yellowing resistance of the MCPU.

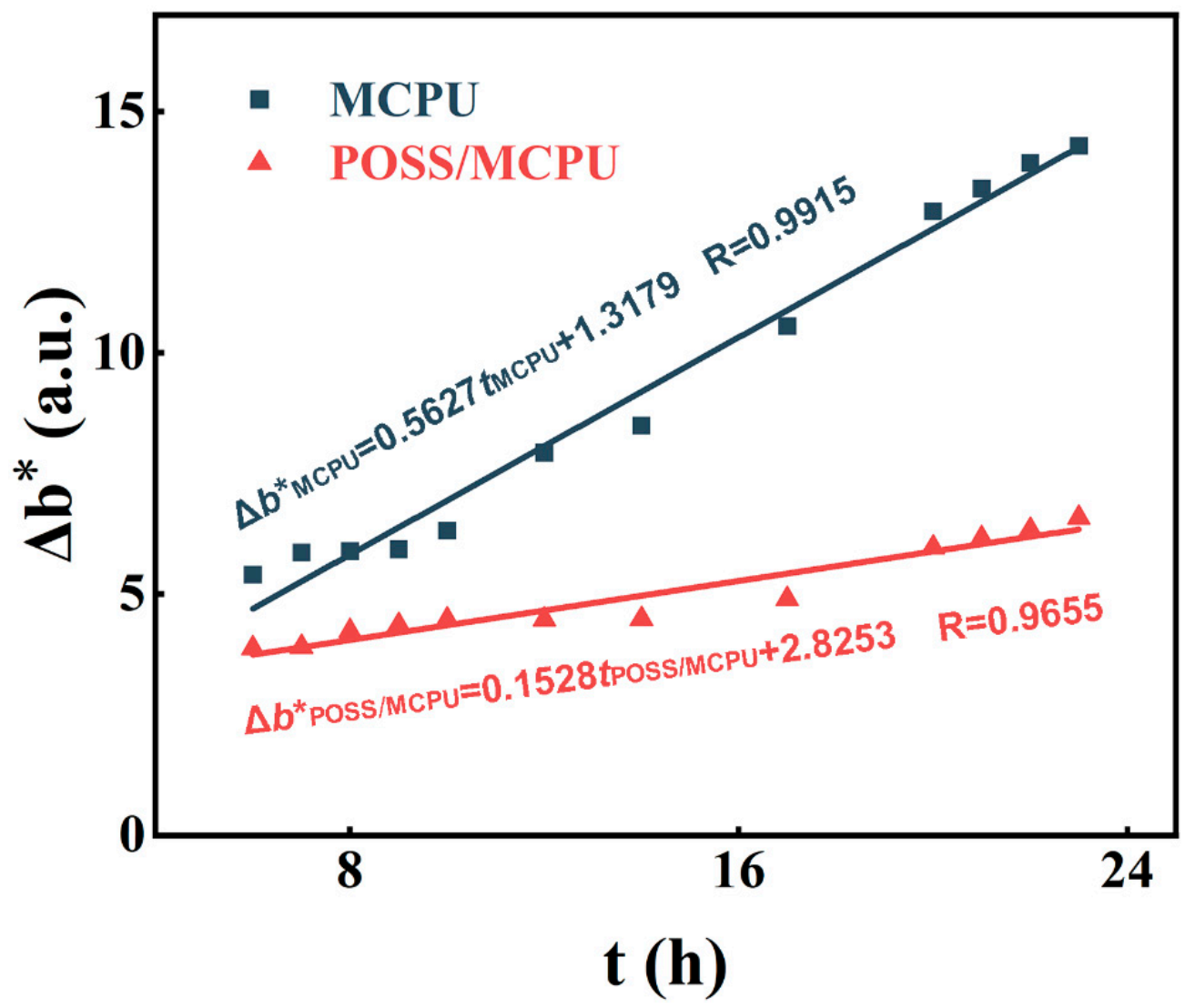

Figure 4. Effect of thermal ageing on MCPU and POSS/MCPU chromaticity.

As shown in Figure 5, the tensile strengths of the MCPU and POSS/MCPU films were 11.63 and $14.81 \mathrm{MPa}$, respectively, an increase of $27.34 \%$. Maximum elongations were $344.97 \%$ and $370.15 \%$, respectively, an improvement of $25.18 \%$. The incorporation of nano-POSS increased the strength and toughness of the films. This is consistent with the results of previous research [24]. 


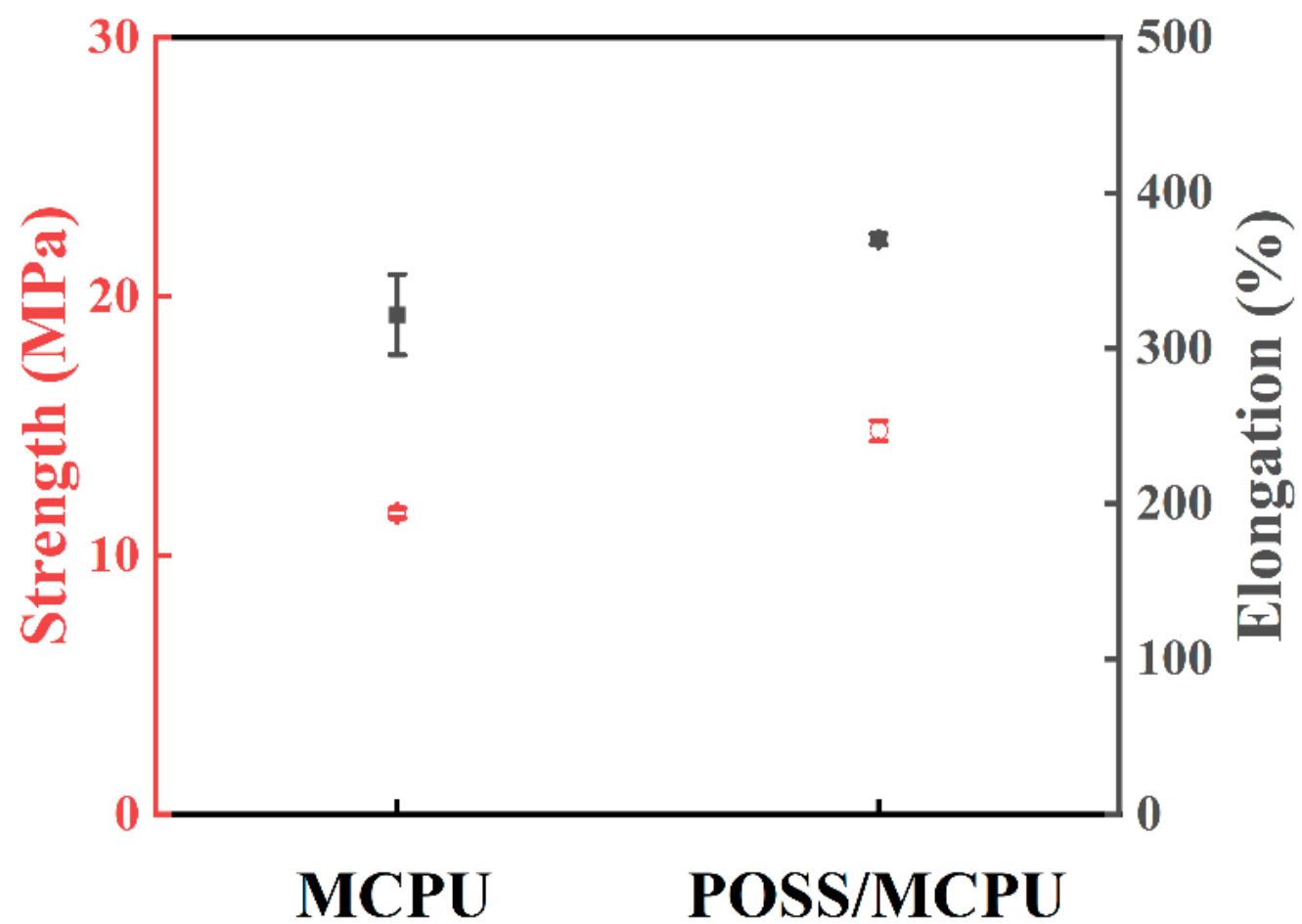

Figure 5. Tensile strength and maximum elongation for MCPU and POSS/MCPU.

Figure 6 shows the SEM images of the fracture surfaces of the MCPU and POSS/MCPU films. The fracture surface of the original MCPU film is flat, while that of the POSS/MCPU film is covered with striated grooves. After POSS incorporation, as a result of the ultrasonic assistance, a well-dispersed inorganic-organic phase is formed in the polymer. When the film fractures, as a single-component polymer, the original MCPU film produces a relatively flat surface, whereas the POSS/MCPU film has both inorganic and organic phases and tends to form a rough structure. The grooved structure increases the bonding force at the fracture interface, which is responsible for the increases in the strength and maximum elongation of the film.
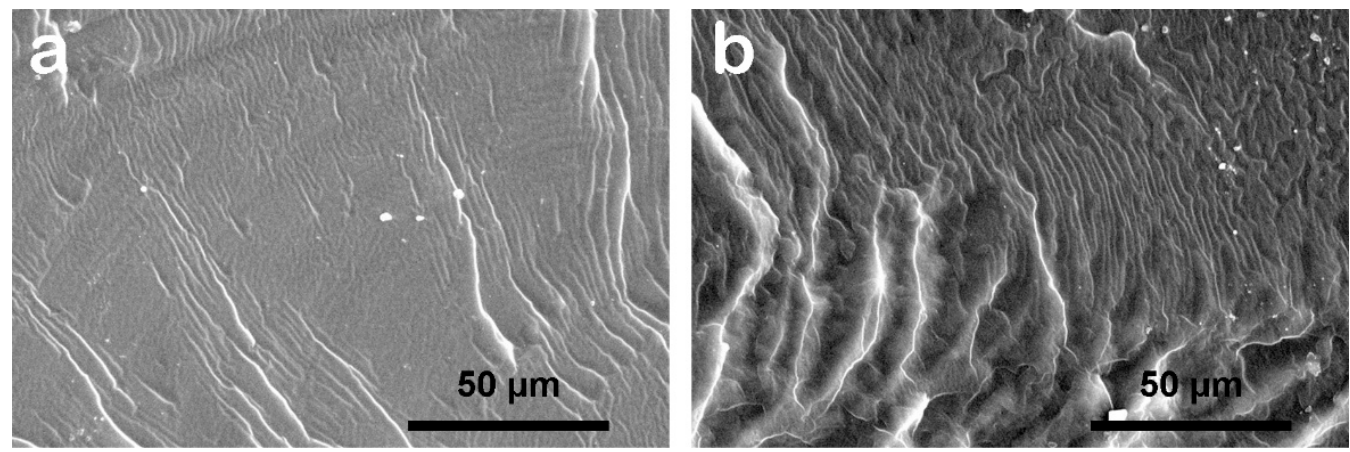

Figure 6. SEM images of MCPU (a) and POSS/MCPU (b) films sections.

In summary, the introduction of POSS does not affect the surface appearance of the film and, meanwhile, improves the heat resistance of the MCPU. This makes it more resistant to yellowing during heat ageing. In addition, the strength and toughness of the film are simultaneously increased.

\subsection{Treatment Results}

The silk fabric samples were processed using POSS/MCPU. It penetrates well as a reinforcement, which enhances the overall strength of fragile artefacts. The GPC results showed 
that the corresponding number-average molecular weights were 1894 and 4842, which are much lower than those of Paraloid B72, resulting in better permeability of POSS/MCPU.

As a general rule, any treatments should not alter the appearance of the cultural objects. Therefore, the color change before and after treatment was tested. As shown in Figure 7, the chromaticity of the silk samples before and after treatment remained almost unchanged, with an average color difference of $\Delta \mathrm{E}$ of 1.49 (unrecognizable to the naked eye), which is in line with the requirements of conservation.

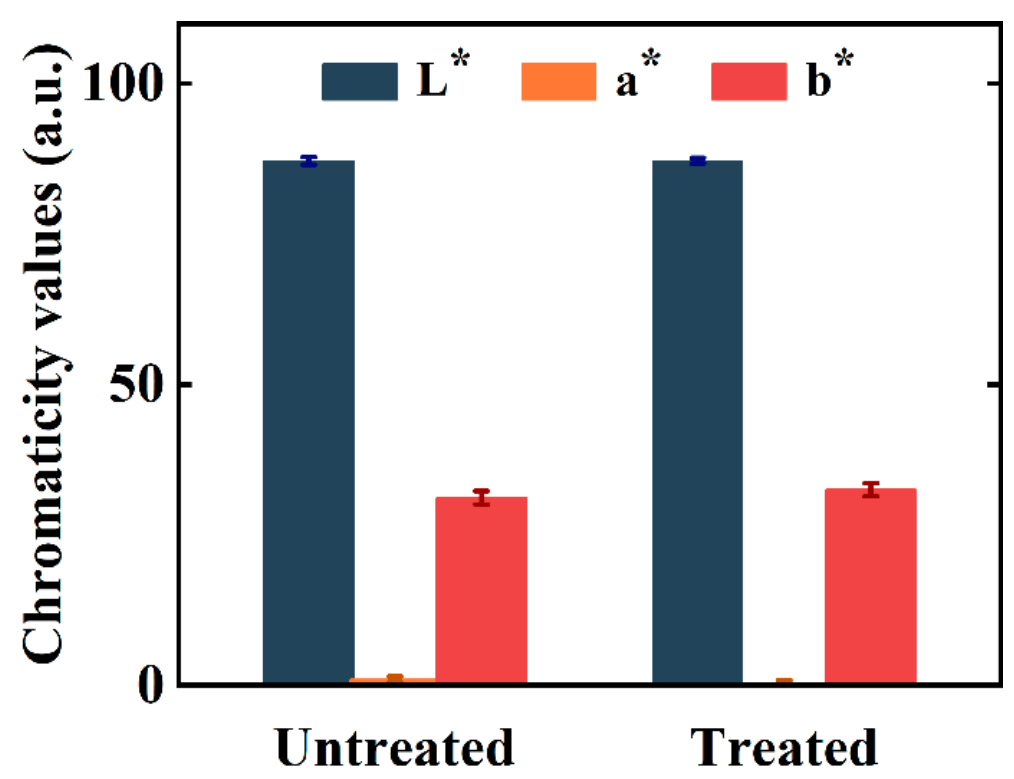

Figure 7. Chromaticity values before and after treatment.

The tensile strength and maximum elongation of the untreated and treated silk samples were tested contrastingly (Figure 8). After treatment, the tensile strength of the silk samples increased from 46.52 to $80.51 \mathrm{MPa}$, an increase in strength of $73.07 \%$. The maximum elongation increased from $5.53 \%$ to $7.30 \%$, an increase of $1.77 \%$. It shows that the treatment of fragile samples with POSS/MCPU simultaneously enhanced their strength and toughness. Therefore, the POSS/MCPU is a potential material for the extraction of fragile organic samples excavated from archaeological sites.

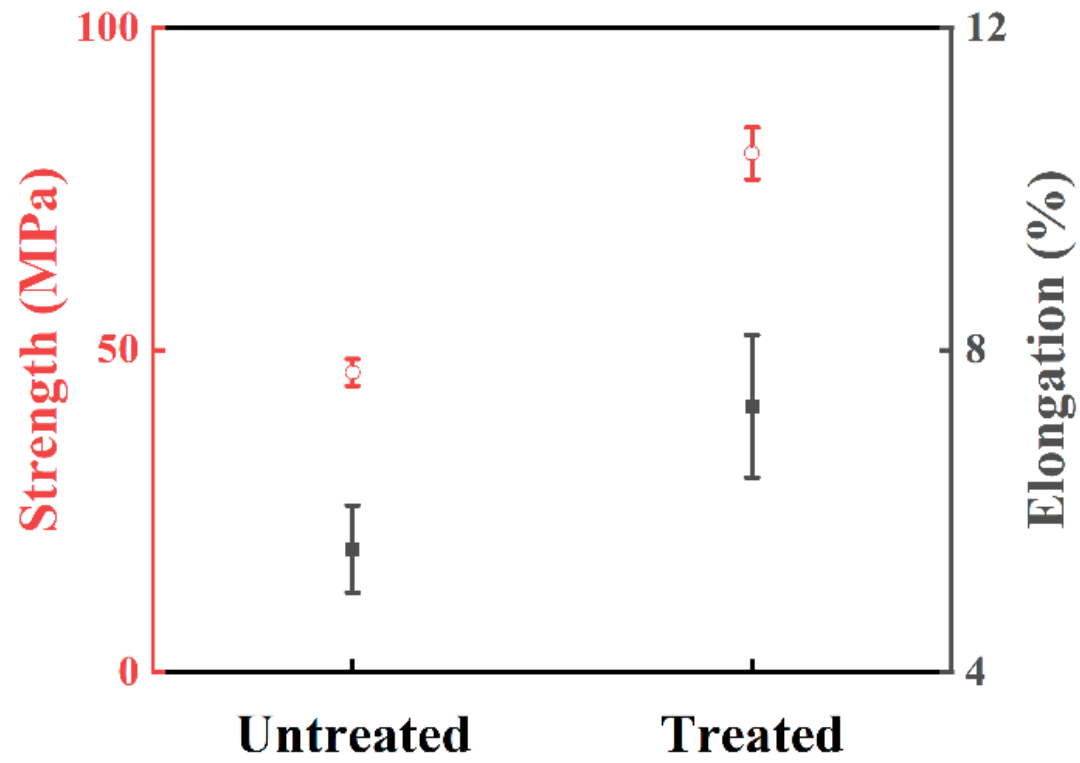

Figure 8. Tensile strength and maximum elongation before and after treatment. 
Overall, the treatment of fragile-artefact samples with POSS/MCPU does not affect the appearance of the samples but does increase their strength and toughness, which is important for the extraction of fragile samples. The newly prepared POSS/MCPU is a suitable material with high performance for the conservation of cultural objects.

\section{Conclusions}

MCPU was modified with POSS as a stabilizer to produce POSS/MCPU, which exhibited excellent thermal stability and good reinforcement properties. The results showed that the addition of POSS improves the thermal stability, resistance to yellowing by heat, the strength and toughness of the film, without affecting its appearance. Satisfactory results were also achieved with the POSS/MCPU-reinforced fragile samples. The newly prepared material has potential to be used for the extraction of fragile organic cultural objects from archaeological sites.

Author Contributions: X.Z. and L.G. contributed equally to this work. X.Z. produced the manuscript and synthesized the MCPU. L.G. revised the manuscript and analyzed the results. M.P. performed the consolidation of samples and interpreted the data. L.W. designed the work and revised the manuscript. Z.W. prepared the POSS/MCPU and performed the characterization. L.Z. and Q.N. interpreted the data for the work and revised the manuscript. All authors have read and agreed to the published version of the manuscript.

Funding: This research was funded by the Key Research and Development Plan of Shaanxi Province (2019ZDLSF07-05), Projects of the Social Science Foundation of Shaanxi Province (2021G001), the Education Department of Shaanxi Province (20JZ092) and the National Social Science Fund of China (17XKG002).

Institutional Review Board Statement: Not applicable.

Informed Consent Statement: Not applicable.

Data Availability Statement: Not applicable.

Acknowledgments: The authors would like to thank Xiaoyan Ma (Northwestern Polytechnical University) for her guidance and the provision of POSS materials.

Conflicts of Interest: The authors declare no conflict of interest.

\section{References}

1. Kapolos, J.; Bakaoukas, N.; Koliadima, A.; Karaiskakis, G. Evaluation of acrylic polymeric resin and small siloxane molecule for protecting cultural heritage monuments against sulfur dioxide corrosion. Prog. Org. Coat. 2007, 59, 152-159. [CrossRef]

2. Sun, B.; Zhang, H.; Zhang, B.; Jiang, D.; Zhang, R.; Tan, X. A scientific investigation of five polymeric materials used in the conservation of murals in Dunhuang Mogao Grottoes. J. Cult. Herit. 2018, 31, 105-111.

3. Xu, J.; Jiang, Y.; Zhang, T.; Dai, Y.; Yang, D.; Qiu, F.; Yu, Z.; Yang, P. Fabrication of UV-curable waterborne fluorinated polyurethaneacrylate and its application for simulated iron cultural relic protection. J. Coat. Technol. Res. 2018, 15, 535-541. [CrossRef]

4. Alonso-Villar, E.M.; Rivas, T.; Pozo-Antonio, J.S. Adhesives applied to granite cultural heritage: Effectiveness, harmful effects and reversibility. Constr. Build. Mater. 2019, 223, 951-964. [CrossRef]

5. Pizzo, B.; Garabelli, G.; Varetto, M.; Brancati, L.E.; Locandieri, M.; Pecoraro, E.; Macchioni, N. On site consolidation of burnt and partially charred wood in dry conditions. J. Cult. Herit. 2011, 12, 19-27. [CrossRef]

6. Rodriguez-Mella, Y.; López-Morán, T.; López-Quintela, M.A.; Lazzari, M. Durability of an industrial epoxy vinyl ester resin used for the fabrication of a contemporary art sculpture. Polym. Degrad. Stabil. 2014, 107, 277-284. [CrossRef]

7. Liu, J.; Jin, S.-S.; Qi, Y.-P.; Shen, Y.-F.; Li, H. Preparation and application of polyurethane coating material based on epoxy cyclohexane protective for paper. Coatings 2021, 11, 431. [CrossRef]

8. Han, X.; Rong, B.; Huang, X.; Luo, H. Bridged siloxanes as novel potential hybrid consolidants for ancient Qin terracotta. Prog. Org. Coat. 2016, 101, 416-422. [CrossRef]

9. Chatzigrigoriou, A.; Karapanagiotis, I.; Poulios, I. Superhydrophobic coatings based on siloxane resin and calcium hydroxide nanoparticles for marble protection. Coatings 2020, 10, 334. [CrossRef]

10. Pargoletti, E.; Comite, V.; Fermo, P.; Sabatini, V.; Cappelletti, G. Enhanced historical limestone protection by new organic/inorganic additive-modified resins. Coatings 2021, 11, 73. [CrossRef]

11. Wang, B. Applicability Study of the Reinforcement Material of the Commonly Used Relics in Different Humidity Environments. Master's Thesis, Northwest University, Xi'an, China, 2017. 
12. Han, X.; Huang, X.; Zhang, B. Morphological studies of menthol as a temporary consolidant for urgent conservation in archaeological field. J. Cult. Herit. 2016, 18, 271-278. [CrossRef]

13. Zhao, Z.C.; Song, Y.C.; Huang, X.; Soh, A.K.; Zhang, D.S. Study of solidification of menthol for the applications in temporary consolidation of cultural heritage. J. Cult. Herit. 2020, 44, 83-89. [CrossRef]

14. Chen, X.; Zhang, B.; Zhang, Z. Application of veratraldehyde as a temporary consolidant for relics at underwater cultural heritage sites. Archaeometry 2019, 61, 1417-1429. [CrossRef]

15. Chen, X.; Zhang, B.; Zhang, Z. A novel method of temporary solidification and extraction of underwater fragile relics in their original state. Int. J. Adhes. Adhes. 2021, 104, 102724. [CrossRef]

16. Wang, X.; Zhang, B.; Hu, Y. Research on extraction of fragile bamboo slips by underwater temporary solidification in original state. J. Cult. Herit. 2021, 51, 174-181. [CrossRef]

17. Zhao, X.; Wang, L.; Zhao, X.; Qian, Y.; Tang, Y.; Dong, X. Synthesis, testing and application of moisture-curable polyurethane as a consolidant for fragile organic cultural objects. J. Adhes. Sci. Technol. 2018, 32, 2421-2428. [CrossRef]

18. Zhao, X.; Wang, L.; Guo, L.; Ma, Y.; Wang, Z.; Niu, Q. The effect of a hindered amine light stabilizer on the aging behavior of moisture-curable polyurethane as a cultural relics consolidant. Polimery 2020, 65, 297-303. [CrossRef]

19. Li, G.; Wang, L.; Ni, H.; Pittman, C.U., Jr. Polyhedral oligomeric silsesquioxane (POSS) polymers and copolymers: A review. J. Inorg. Organomet. Polym. 2002, 11, 123-154. [CrossRef]

20. Liu, H.; Zheng, S. Polyurethane networks nanoreinforced by polyhedral oligomeric silsesquioxane. Macromol. Rapid Commun. 2005, 26, 196-200. [CrossRef]

21. Janowski, B.; Pielichowski, K. Thermo(oxidative) stability of novel polyurethane/POSS nanohybrid elastomers. Thermochim. Acta 2008, 478, 51-53. [CrossRef]

22. Chattopadhyay, D.K.; Webster, D.C. Thermal stability and flame retardancy of polyurethanes. Prog. Polym. Sci. 2009, 34, 1068-1133. [CrossRef]

23. Zhang, W.; Camino, G.; Yang, R. Polymer/polyhedral oligomeric silsesquioxane (POSS) nanocomposites: An overview of fire retardance. Prog. Polym. Sci. 2017, 67, 77-125. [CrossRef]

24. Behera, P.K.; Mondal, P.; Singha, N.K. Self-healable and ultrahydrophobic polyurethane-POSS hybrids by Diels-Alder "click" reaction: A new class of coating material. Macromolecules 2018, 51, 4770-4781. [CrossRef]

25. Lewicki, J.P.; Pielichowski, K.; de La Croix, P.T.; Janowski, B.; Todd, D.; Liggat, J.J. Thermal degradation studies of polyurethane/POSS nanohybrid elastomers. Polym. Degrad. Stabil. 2010, 95, 1099-1105. [CrossRef]

26. Lu, C.; Tian, C.; Wang, J. Preparation and characterization of POSS/PUE nanocomposites. Mater. Rep. 2010, $24,111-114$.

27. Tian, C.; Wang, J.; Sun, J.; Liang, S.; Cheng, K. Preparation of polyhedral oligomeric silsesquioxane modified polyurethane. China Rubber Ind. 2011, 58, 404-409.

28. Vyazovkin, S.; Dranca, I.; Fan, X.; Advincula, R. Degradation and relaxation kinetics of polystyrene-clay nanocomposite prepared by surface initiated polymerization. J. Phys. Chem. B 2004, 108, 11672-11679. [CrossRef] 